\title{
Elevated Monocyte-to-High-Density Lipoprotein Ratio as an Indicator of Systemic Inflammation in Patients with Branch Retinal Vein Occlusion
}

\author{
(1) Zeynep Duru, ${ }^{1}$ (1) Orhan Altunel, ${ }^{2}$ (1) Bedirhan Alabay, ${ }^{1}$ (1) Ender Sirakaya, \\ (1) Bekir Kucuk, ${ }^{1}$ (D) Musa Musaoglu ${ }^{3}$ \\ ${ }^{1}$ Department of Ophthalmology, Kayseri City Hospital, Kayseri, Turkey \\ ${ }^{2}$ Department of Ophthalmology, Kutahya Health Sciences University, Kutahya, Turkey \\ ${ }^{3}$ Department of Ophthalmology, Yenikent State Hospital, Sakarya, Turkey
}

\begin{abstract}
Objectives: This study was designed to assess the monocyte-to-high-density lipoprotein (HDL) ratio (MHR) as a possible marker of systemic inflammation in patients with branch retinal vein occlusion (BRVO).

Methods: A study group of 62 patients with BRVO and a control group of 60 age-matched, healthy individuals were enrolled in the study. The blood lipid profile, hematology profile, and C-reactive protein (CRP) level were measured. The MHR was calculated as the ratio of the monocyte count to the HDL level, and the neutrophil-to-lymphocyte ratio (NLR) was calculated as the ratio of the neutrophil count to the lymphocyte count.

Results: In patients with BRVO versus controls, the mean MHR was $14.1 \pm 5$.I vs $12.2 \pm 4.3$ ( $p=.032$ ), the mean NLR was $1.99 \pm 0.69$ vs $2.01 \pm 0.86(p=.889)$, and the mean CRP level was $3.44 \pm 2.53 \mathrm{mg} / \mathrm{L}$ vs $2.8 \mathrm{I} \pm 1.57 \mathrm{mg} / \mathrm{L}(p=.102)$. The area under the receiver operating characteristic curve for the MHR and the NLR was 0.621 and 0.519 , respectively. The sensitivity and specificity of the MHR and the NLR to predict BRVO was $51 \%$ and $73 \%$ vs $79 \%$ and $35 \%$, respectively.

Conclusion: The MHR values were higher in patients with BRVO compared with those of the control group. BRVO seems to be associated with systemic inflammation.

Keywords: Branch retinal vein occlusion, inflammation, monocyte-to-high-density lipoprotein ratio, MHR
\end{abstract}

\section{Introduction}

The second most common vision-threatening vascular disorder in the retina, branch retinal vascular occlusion (BRVO) typically occurs at arteriovenous intersections where the venule and arteriole share an adventitial sheath (I). The increased rigidity of the crossing artery due to atherosclerotic disease may compress the underlying vein and cause turbu- lent blood flow, endothelial damage, and thrombus formation. Consequently, arterial hypertension and hypercholesterolemia are both known to contribute to atherogenesis and are defined as risk factors of BRVO (2-4).

Amid recently increased interest in how inflammation affects the pathogenesis of retinal vein occlusion, researchers have shown that local and systemic inflammation plays a role

How to cite this article: Duru Z, Altunel O, Alabay B, Sirakaya E, Kucuk B, Musaoglu M. Elevated Monocyte-to-High-Density Lipoprotein Ratio as an Indicator of Systemic Inflammation in Patients with Branch Retinal Vein Occlusion. Beyoglu Eye J 2021; 6(3): 212-216.

Address for correspondence: Orhan Altunel, MD. Kutahya Saglik Bilimleri Universitesi, Goz Hastaliklari Anabilim Dali, Kutahya, Turkey Phone: +90 2742236056 E-mail: orhan_altunel@hotmail.com

Submitted Date: December 12, 2020 Accepted Date: May 10, 2021 Available Online Date: September 24,2021

${ }^{\circ}$ Copyright 2021 by Beyoglu Eye Training and Research Hospital - Available online at www.beyoglueye.com OPEN ACCESS This work is licensed under a Creative Commons Attribution-NonCommercial-ShareAlike 4.0 International License. 
in the development of retinal vein occlusion by inducing both atherosclerosis and conditions for systemic hypercoagulability (5). Atherosclerosis is a low-grade, chronic inflammatory disorder characterized by a distinct pro-inflammatory $\mathrm{THI}$ cytokine pattern and the recruitment of $\mathrm{T}$ lymphocytes and monocytes to sites of inflammation (6). Lately, laboratory and clinical trials have also sought to elucidate the molecular pathways responsible for inflammation (7).

Due to the pro-inflammatory effects of monocytes and the anti-inflammatory effect of high-density lipoprotein (HDL), researchers have recently identified the ratio of monocytes to HDL (MHR) as a possible indicator of systemic inflammation. Previously, researchers have investigated the role of MHR in several well-known diseases (8-II). In this study, we aimed to evaluate MHR as a possible indicator of systemic inflammation in patients with BRVO.

\section{Methods}

\section{Population and Design}

Conducted in the department of ophthalmology, our cross-sectional study followed the tenets of the Declaration of Helsinki and received approval from the local ethics committee. All potential participants received both oral and written information about the study, and each willing participant provided his or her written informed consent to participate. The sample ultimately consisted of $62 \mathrm{pa}-$ tients with BRVO and, as controls, 60 healthy, age-matched individuals without any ocular or systemic disease, except for controlled hypertension, who had applied for pre-operative evaluations for the upper eyelid blepharoplasty surgery. Each participant underwent a comprehensive ophthalmic evaluation involving Goldmann applanation tonometry to measure intraocular pressure, Snellen charts to measure best-corrected visual acuity, slit-lamp biomicroscopy, and a dilated stereoscopic fundus examination. We diagnosed BRVO according to the results of stereoscopic fundus examinations for participants with retinal venous dilation and tortuosity accompanied by flame- and wedge-shaped regions of intraretinal hemorrhage.

\section{Exclusion Criteria}

Ocular exclusion criteria for participation were any history of significant ocular disease, ocular surgery, uveitis, scleritis, retinal disease (except for BRVO), ocular trauma, or dense media opacities. Extraocular exclusion criteria were any history of systemic disease, including uncontrolled hypertension, renal failure, chronic obstructive pulmonary disease, hepatic disorders, anemia, malignancy, acute infectious disease, chronic systemic inflammatory disease, hyperlipidemia, thyroid abnormalities, cardiac disease, diabetes mellitus, autoimmune disease, and connective tissue disease. We also excluded all individuals who use tobacco, consume alcohol, or receive treatment involving any systemic medications that could affect hematological parameters (e.g., antihyperlipidemic therapy).

\section{Blood Samples}

After performing the comprehensive ophthalmic examinations, we measured the blood lipid profiles, hematology profiles, and C-reactive protein (CRP) levels of participants. We collected all blood samples from the antecubital veins of participants between 09:00 and I I:00 a.m. after they had fasted overnight within $24 \mathrm{~h}$ of initial diagnosis of BRVO, and recorded all hematological parameters. We calculated MHR as the ratio of the monocyte count to the level of HDL and the neutrophil-to-lymphocyte ratio (NLR) as the ratio of the neutrophil count to the lymphocyte count.

\section{Statistical Analysis}

We performed all statistical tests in the Statistical Package for the Social Sciences version 21 and present all data as mean $\pm S D$. For each continuous variable, we assessed normality using the Kolmogorov-Smirnov test. To compare results between the study and control groups, we subjected data of categorical variables to a Chi-square test and data of continuous variables to an independent $t$ test. A receiver operating characteristic analysis was performed to determine the specificity and sensitivity of biomarker and the discriminative value of intergroup differences for MHR and NLR. Finally, we measured the Pearson correlation coefficient for correlation analysis and considered that all $p<0.05$ indicated statistical significance.

\section{Results}

The sample consisted of 62 individuals with BRVO, aged $64.34 \pm 8.58$ years (range: $47-85$ ), and 60 healthy, age-

Table I. Baseline characteristics of patients with branch retinal vein occlusion (BRVO, $n=62)$ and healthy, age-matched controls $(n=60)$

\begin{tabular}{lccc} 
Parameters & BRVO & Control & P \\
\hline $\begin{array}{l}\text { Sex, n (\%) } \\
\text { Female }\end{array}$ & $28(45)$ & $31(52)$ & $.472^{*}$ \\
$\quad$ Male & $34(55)$ & $29(48)$ & \\
Hypertension, n (\%) & & & \\
$\quad$ Positive & $44(71)$ & $38(63)$ & $.369^{*}$ \\
Negative & $18(29)$ & $22(37)$ & \\
Age, year & & & \\
$\quad$ Mean $\pm S D$ & $64.34 \pm 8.58$ & $62.60 \pm 8.91$ & $.274^{* *}$ \\
Range & $47-85$ & $48-81$ & \\
\hline
\end{tabular}

SD: Standard deviation; ${ }^{*}:$ Chi-square test, ${ }^{*}$ : Independent t-test. 
Table 2. Laboratory data of patients with branch retinal vein occlusion (BRVO, $n=62)$ and healthy, age-matched controls $(n=60)$

\begin{tabular}{|c|c|c|c|}
\hline \multirow[t]{2}{*}{ Variables } & \multirow{2}{*}{$\begin{array}{c}\text { BRVO } \\
\text { Mean } \pm S D\end{array}$} & \multirow{2}{*}{$\begin{array}{c}\text { Control } \\
\text { Mean } \pm \text { SD }\end{array}$} & \multirow[t]{2}{*}{$\mathbf{p}^{*}$} \\
\hline & & & \\
\hline Neutrophil count, $10^{3} / \mathrm{IL}$ & $4.45 \pm 1.05$ & $4.14 \pm 1.03$ & .103 \\
\hline Lymphocyte count, $10^{3} / \mathrm{IL}$ & $2.36 \pm 0.53$ & $2.24 \pm 0.59$ & .272 \\
\hline Monocyte count, $10^{3} / \mathrm{IL}$ & $0.60 \pm 0.16$ & $0.55 \pm 0.14$ & .118 \\
\hline Platelet count, $10^{3} / \mathrm{IL}$ & $257.5 \pm 49.9$ & $255.8 \pm 41.7$ & .836 \\
\hline Haemoglobin (g/dL) & $14.28 \pm 1.72$ & $14.63 \pm 1.99$ & .294 \\
\hline Hematocrit (\%) & $42.61 \pm 4.23$ & $43.98 \pm 5.06$ & .108 \\
\hline Total cholesterol (mg/dL) & $193.29 \pm 35.66$ & $196.80 \pm 45.16$ & .634 \\
\hline HDL cholesterol (mg/dL) & $45.15 \pm 10.18$ & $47.63 \pm 8.38$ & .144 \\
\hline LDL cholesterol (mg/dL) & $115.69 \pm 33.46$ & $118.68 \pm 35.76$ & .634 \\
\hline Triglycerides (mg/dL) & $162.23 \pm 62.37$ & $152.43 \pm 65.38$ & .399 \\
\hline C-reactive protein (mg/dL) & $3.44 \pm 2.53$ & $2.8 I \pm 1.57$ & .102 \\
\hline $\mathrm{ESR},(\mathrm{mm} / \mathrm{h})$ & $9.61 \pm 4.53$ & $9.03 \pm 4.47$ & .479 \\
\hline
\end{tabular}

HDL: High-density lipoprotein; LDL: Low-density lipoprotein; ESR: Erythrocyte sedimentation rate; SD: Standard deviation; *: Independent t-test.

Table 3. Monocyte-to-high density lipoprotein ratio (MHR) and neutrophil-to-lymphocyte ratio (NLR) between patients with branch retinal vein occlusion (BRVO, $\mathrm{n}=62$ ) and healthy, age-matched controls $(n=60)$

\begin{tabular}{|c|c|c|c|}
\hline \multirow[t]{2}{*}{ Variables } & \multirow{2}{*}{$\begin{array}{c}\text { BRVO } \\
\text { Mean士SD }\end{array}$} & \multirow{2}{*}{$\frac{\text { Control }}{\text { Mean } \pm S D}$} & \multirow[t]{2}{*}{$\mathbf{p}^{*}$} \\
\hline & & & \\
\hline MHR & $|4.| \pm 5 . \mid$ & $12.2 \pm 4.3$ & .032 \\
\hline NLR & $1.99 \pm 0.69$ & $2.0 I \pm 0.86$ & .889 \\
\hline
\end{tabular}

*: Independent t-test. SD: Standard deviation.

matched individuals, aged $62.60 \pm 8.91$ years (range: 48-8I; $\mathrm{p}=.274$ ). The baseline demographic characteristics (Table I) and laboratory data (Table 2) between patients with BRVO and controls indicated no statistically significant difference between the groups. As shown in Table 3, mean MHR was I4.I \pm 5.1 among patients with BRVO and $12.2 \pm 4.3$ among controls $(p=0.032)$, whereas mean NLR was $1.99 \pm 0.69$ among patients with BRVO and $2.01 \pm 0.86$ among controls $(p=0.889)$. The results of correlation analysis (Table 4) revealed that MHR did not correlate with CRP or NLR in patients with BRVO. On the receiver operating characteristics curve, the area under the curve was 0.621 for MHR and 0.519 for NLR. The optimal cutoff value was 13.97 with $51 \%$ sensitivity and $73 \%$ specificity for MHR and 1.44 with $79 \%$ sensitivity and $35 \%$ specificity for NLR (Fig. I).
Table 4. Correlation analysis between MHR and other laboratory data among patients with branch retinal vein occlusion (BRVO, $n=62$ )

\begin{tabular}{lcc} 
& \multicolumn{2}{c}{ MHR } \\
\cline { 2 - 3 } & $\mathbf{R}$ & $\mathbf{p}^{*}$ \\
\hline Neutrophil & .195 & .129 \\
Lymphocyte & .166 & .197 \\
Platelet & -.169 & .188 \\
Haemoglobin & .218 & .088 \\
Hematocrit & .200 & .119 \\
Total cholesterol & -.055 & .669 \\
LDL cholesterol & -.038 & .767 \\
Triglycerides & .121 & .347 \\
C-reactive protein & .032 & .805 \\
ESR & -.243 & .057 \\
NLR & -.007 & .957 \\
\hline
\end{tabular}

NLR: Neutrophi//lymphocyte ratio; LDL: Low-density lipoprotein; ESR: Erythrocyte sedimentation rate. *: Pearson correlation test.

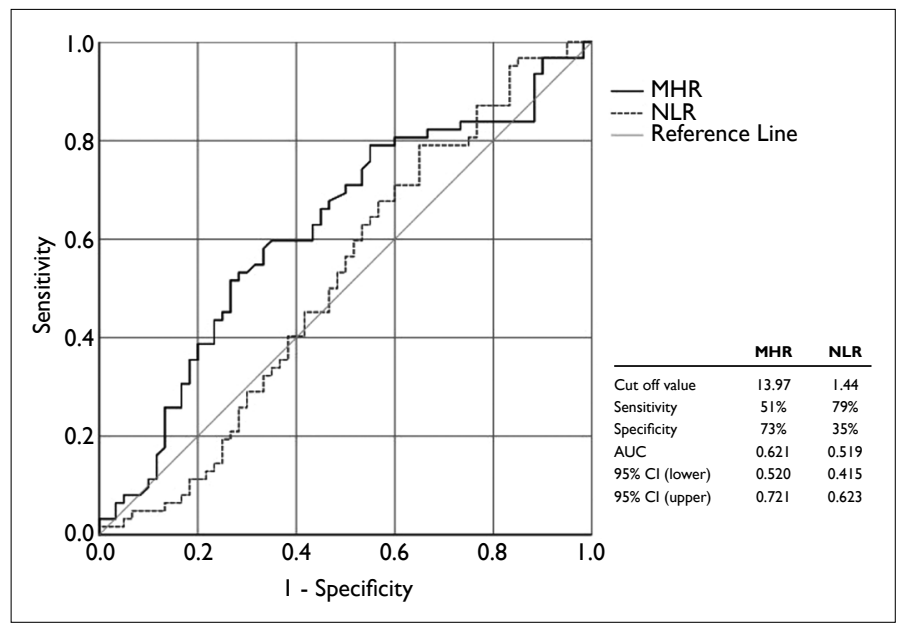

Figure I. The receiver operating characteristics analysis for monocyte-to- high-density lipoprotein ratio (MHR) and neutrophil-to-lymphocyte ratio (NLR) in predicting branch retinal vein occlusion (BRVO). AUC:Area under the curve; $\mathrm{Cl}$ : Confidence interval.

\section{Discussion}

Local and systemic types of inflammation are important etiological factors of BRVO, among which vascular and inflammatory mediators are especially salient, and systemic inflammation is thought to play a particularly important role in the condition's etiology (12-14). Predisposing systemic risk factors for BRVO include dyslipidemia, high levels of plasma homocysteine, hypertension, and diabetes, all of which are also independently associated with atherosclerosis, a disease whose relationship with BRVO has been studied in detail 
(2-5). Initial pathological findings of atherosclerosis indicate T-lymphocytes and monocyte-derived macrophages that later progress to form thrombi and clots (I5).

In recent studies, researchers have investigated MHR in relation to diseases such as chronic kidney disease, cardiovascular disease, and endothelial dysfunction (16-20). In inflammatory conditions, monocytes play an important role in the release of pro-inflammatory and pro-oxidative cytokines. By contrast, HDL cholesterol molecules inhibit the migration of monocytes in response to oxidized low-density lipoprotein and the expression of endothelial adhesion proteins, and consequently, HDL exhibits anti-inflammatory properties (2I). Consequently, MHR has emerged as a potential indicator of inflammation calculated by dividing monocyte counts amid inflammation by the level of anti-inflammatory HDL. Therefore, our study aimed to clarify the association between MHR and BRVO.

We evaluated MHR as a different marker of systemic inflammation in patients with BRVO. Among our results, MHR was significantly higher among patients with BRVO than controls, although the between-group difference in NLR was not statistically significant. Patients with BRVO also exhibited CRP levels higher than those among controls, although not to a statistically significant degree. In the previous studies conducted to evaluate laboratory findings representing patients with BRVO, Kumral et al. (22) assessed mean platelet volume (MPV) and NLR; since neither of them seemed to be affected by BRVO, their results suggested that NLR cannot be used to predict inflammation in relation to BRVO. Conversely, Dursun et al. (23) reported that higher NLR is associated with the development of retinal vein occlusion, the risk of which NLR might be used to predict. In another study, Onder et al. (24) evaluated MPV in BRVO and reported that MPV was significantly higher in patients with hypertensive BRVO, which contradicted the results of Kumral et al. Recently, Şatırtav et al. (25) reported that elevated MHR is significantly associated with BRVO, which was consistent with our study.

Given those findings and our results, we suggest that MHR is a better indicator of systemic inflammation than other hematological parameters in inflammatory disorders, largely because MHR indicates the balance of pro-inflammatory and anti-inflammatory reactions. Monocytes and macrophages, both responsible for pro-inflammatory and pro-oxidant reactions, play a key role in inflammatory reactions because their activation prompts inflammatory cytokine synthesis. Conversely, HDL decreases macrophage accumulation, inhibits the migration of monocytes, increases the expression of nitric oxide synthase in endothelial tissues, protects endothelial cells, and exhibits antioxidant and anti-inflammatory activity (26). Consequently, MHR might be more predictive of systemic inflammation than other markers.
Our study had also one limitation. We used a simple baseline determination that might not reflect a patient's long-term status.

Altogether, inflammation seems to play an important role in BRVO. We suggest that MHR can be a useful, practical, inexpensive, and easily measured indicator of systemic inflammation to predict the risk of developing BRVO. However, further studies are necessary to evaluate the role of MHR on prognosis and treatment response of BRVO in larger samples.

\section{Disclosures}

Ethics Committee Approval: Erciyes University Ethics Committee, 2019/296, 08.06.2019.

Peer-review: Externally peer-reviewed.

Conflict of Interest: None declared.

Authorship Contributions: Involved in design and conduct of the study (ZD, OA); preparation and review of the study (ZD, OA); data collection (BA, ES); and statistical analysis (BK, MM).

\section{References}

I. Yau JW, Lee P, Wong TY, Best J, Jenkins A. Retinal vein occlusion: An approach to diagnosis, systemic risk factors and management. Intern Med J 2008;38:904-10. [CrossRef]

2. Rehak J, Rehak M. Branch retinal vein occlusion: pathogenesis, visual prognosis, and treatment modalities. Curr Eye Res 2008;33: I I -3I. [CrossRef]

3. Wong TY, Larsen EK, Klein R, Mitchell P, Couper DJ, Klein BE, et al. Cardiovascular risk factors for retinal vein occlusion and arteriolar emboli: the Atherosclerosis Risk in Communities \& Cardiovascular Health studies. Ophthalmology 2005; I I2:540-7.

4. Cheung N, Klein R, Wang JJ, Cotch MF, Islam AF, Klein BE, et al. Traditional and novel cardiovascular risk factors for retinal vein occlusion: the multiethnic study of atherosclerosis. Invest Ophthalmol Vis Sci 2008;49:4297-302. [CrossRef]

5. Kesler A, Shalev V, Rogowski O, Shimron O, Shainberg B, Sela BA, et al. Comparative analysis of homocysteine concentrations in patients with retinal vein occlusion versus thrombotic and atherosclerotic disorders. Blood Coagul Fibrinolysis 2008; 19:259-62. [CrossRef]

6. Ross R. Atherosclerosis an inflammatory disease. New Eng J Med 1999;340: I I5-26. [CrossRef]

7. Deobhakta A, Chang LK. Inflammation in retinal vein occlusion. Int J Inflam 2013;2013:4384 I2. [CrossRef]

8. Vural G, Gümüsyayla Ş. Monocyte-to-high density lipoprotein ratio is associated with a decreased compound muscle action potential amplitude in patients with diabetic axonal polyneuropathy. Medicine (Baltimore) 2018;97:e I2857. [CrossRef]

9. Ganjali S, Gotto AM Jr, Ruscica M, Atkin SL, Butler AE, Banach $M$, et al. Monocyte-to-HDL-cholesterol ratio as a prognostic marker in cardiovascular diseases. J Cell Physiol 2018;233:923746. [CrossRef] 
10. Usta A, Avci E, Bulbul CB, Kadi H, Adali E. The monocyte counts to HDL cholesterol ratio in obese and lean patients with polycystic ovary syndrome. Reprod Biol Endocrinol 2018;16:34.

II. Yılmaz M, Kayançiçek $H$. A new inflammatory marker: elevated monocyte to HDL cholesterol ratio associated with smoking. J Clin Med 2018;7:76. [CrossRef]

12. Sperduto RD, Hiller R, Chew E, Seigel D, Blair N, Burton TC, et al. Risk factors for hemiretinal vein occlusion: comparison with risk factors for central and branch retinal vein occlusion: the eye disease case-control study. Ophthalmology 1998;105:7657I. [CrossRef]

13. Jain S, Hurst JR, Thompson JR, Eke T. UK national survey of current practice and experience of intravitreal triamcinolone acetonide. Eye (Lond) 2009;23: I I64-7. [CrossRef]

14. Ladjimi A, Zeghidi H, Ben Yahia S, Zaouali S, Jenzri S, Messaoud $R$, et al. Traitement des oedèmes maculaires par injection intravitréenne d'acétonide de triamcinolone [Intravitreal injection of triamcinolone acetonide for the treatment of macular edema]. J Fr Ophtalmol 2005;28:749-57.

15. Stary HC, Chandler AB, Glagov S, Guyton JR, Insull W Jr, Rosenfeld $M E$, et al. A definition of initial, fatty streak, and intermediate lesions of atherosclerosis. A report from the Committee on Vascular Lesions of the Council on Arteriosclerosis, American Heart Association. Circulation 1994;89:2462-78.

16. Ucar FM. A potential marker of bare metal stent restenosis: monocyte count - to- HDL cholesterol ratio. BMC Cardiovasc Disord 2016;16:186. [CrossRef]

17. Kormaz A, Demir M, Unal S, Yildiz A, Ozyazgan B, Demirtas $B$, et al. Monocyte-to-high density lipoprotein ratio (MHR) can predict the significance of angiographically intermediate coronary lesions. Int J Cardiovasc Acad 20 I7;3:16-20. [CrossRef]

18. Canpolat U, Çetin EH, Cetin S, Aydin S, Akboga MK, Yayla C, et al. Association of monocyte-to-HDL cholesterol ratio with slow coronary flow is linked to systemic inflammation. Clin Appl Thromb Hemost 2016;22:476-82.

19. Kanbay M, Solak Y, Unal HU, Kurt YG, Gok M, Cetinkaya H, et al. Monocyte count/HDL cholesterol ratio and cardiovascular events in patients with chronic kidney disease. Int Urol Nephrol 2014;46:1619-25. [CrossRef]

20. Cetin MS, Ozcan Cetin EH, Kalender E, Aydin S, Topaloglu S, Kisacik HL, et al. Monocyte to HDL cholesterol ratio predicts coronary artery disease severity and future major cardiovascular adverse events in acute coronary syndrome. Heart Lung Circ 2016;25:1077-86. [CrossRef]

21. Barter PJ, Baker PW, Rye KA. Effect of high-density lipoproteins on the expression of adhesion molecules in endothelial cells. Curr Opin Lipidol 2002; 13:285-8. [CrossRef]

22. Turkseven Kumral E, Yenerel NM, Ercalik NY, Imamoglu S, Vural ET. Neutrophil/lymphocyte ratio and mean platelet volume in branch retinal vein occlusion. Saudi J Ophthalmol 2016;30:1058. [CrossRef]

23. Dursun A, Ozturk S, Yucel H, Ozec AV, Dursun FG, Toker $\mathrm{MI}$, et al. Association of neutrophil/lymphocyte ratio and retinal vein occlusion. Eur J Ophthalmol 2015;25:343-6. [CrossRef]

24. Onder HI, Kilic AC, Kaya M, Bulur S, Onder E, Tunc M. Relation between platelet indices and branch retinal vein occlusion in hypertensive patients. Indian J Ophthalmol 2013;61:160-2.

25. Şatırtav G, Mirza E, Oltulu R, Mirza GD, Kerimoğlu H. Assessment of monocyte/HDL ratio in branch retinal vein occlusion. Ocul Immunol Inflamm 2020;28:463-7. [CrossRef]

26. Ancuta P, Wang J, Gabuzda D. CDI6+ monocytes produce IL-6, CCL2, and matrix metalloproteinase-9 upon interaction with CX3CLI-expressing endothelial cells. J Leukoc Biol 2006;80: I I56-64. 